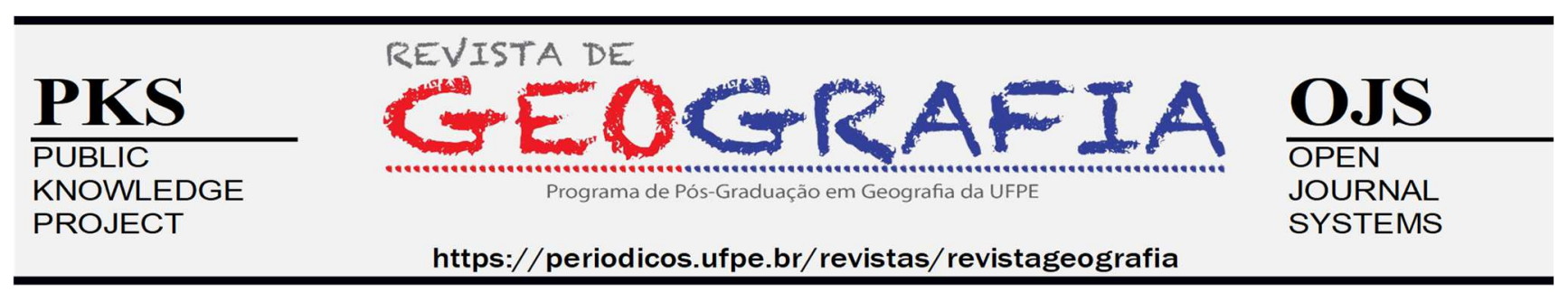

\title{
MIGRAÇÕES NORDESTINAS NO SÉCULO 21: RESENHA
}

\author{
Nilson Cortez Crocia de Barros ${ }^{1}$
}

${ }^{1}$ Universidade Federal de Pernambuco. E-mail: nccrocia@ufpe.br. ORCID: 0000-0002-7633-3085

Resenha recebida em 04/08/2020 e aceito em 01/03/2021

\begin{abstract}
RESUMO
O livro Migrações Nordestinas no Século 21 é uma coletânea com 8 trabalhos de pesquisadores em População \& Demografia interessados na investigação e na avaliação dos processos e dos padrões demográficos experimentados nas últimas décadas por esta região do Brasil. As análises e as conclusões oferecidas apoiam-se nos dados demográficos, sociais e econômicos produzidos e disponibilizados pelo Instituto Brasileiro de Geografia e Estatística (IBGE). Resultam estes oito textos das pesquisas desenvolvidos no âmbito do Projeto "Urbanização, Condições de Vida e Mobilidade Espacial da População no contexto dos Biomas Nordestinos”, financiado pelo Conselho Nacional de Desenvolvimento Científico \& Tecnológico (CNPQ) e conduzido pelo Professor Dr. Ricardo Ojima no Departamento de Demografia da Universidade Federal do Rio Grande do Norte.
\end{abstract}

Palavras-chave: Migrações Nordestinas; População; Demografia

\section{ST CENTURY MIGRATION IN NORTH EAST BRAZIL: A REVIEW}

\begin{abstract}
The book Migrations Northeastern in the 21 st Century is a collection of 8 works by researchers in Population \& Demography interested in the investigation and evaluation of the demographic processes and patterns experienced in the last decades in this region of Brazil. The analyzes and conclusions offered are based on demographic, social and economic data produced and made available by the Brazilian Institute of Geography and Statistics (IBGE). These eight research texts result from the Project "Urbanization, Living Conditions and Spatial Mobility of the Population in the context of Northeastern Biomes", funded by the National Council for Scientific \& Technological Development (CNPQ) and conducted by Professor Dr. Ricardo Ojima in Demography Department of the Federal University of Rio Grande do Norte
\end{abstract}

Keywords: Northeastern migrations; Population; Demography

\section{MIGRATION AU NORD EST DU BRÉSIL AU SIÈCLE 21: REVUE}

\begin{abstract}
ABSTRAIT
Le livre Migrations Northeastern in the 21st Century est une collection de 8 travaux de chercheurs en Population et Démographie intéressés par l'investigation et l'évaluation des processus et des modèles démographiques expérimentés au cours des dernières décennies dans cette région du Brésil. Les analyses et conclusions proposées sont basées sur des données démographiques, sociales et économiques produites et mises à disposition par l'Institut brésilien de géographie
\end{abstract}


et de statistique (IBGE). Ces huit textes de recherche sont issus du projet «Urbanisation, conditions de vie et mobilité spatiale de la population dans le contexte des biomes du nord-est», financé par le Conseil national du développement scientifique et technologique (CNPQ) et dirigé par le professeur Dr. Ricardo Ojima en démographie Département de l'Université fédérale de Rio Grande do Norte.

Mots clés: Migrations du nord-est; Population; Démographie

Ojima, R. \& Fusco, W. (Org.). Migrações nordestinas no século 21: um panorama recente. São Paulo: Edgard Blücher, 2015.

O livro Migrações Nordestinas no Século 21 é uma coletânea com 8 trabalhos de pesquisadores em População \& Demografia interessados na investigação e na avaliação dos processos e dos padrões demográficos experimentados nas últimas décadas por esta região do Brasil. As análises e as conclusões oferecidas apoiam-se nos dados demográficos, sociais e econômicos produzidos e disponibilizados pelo Instituto Brasileiro de Geografia e Estatística (IBGE). Resultam estes oito textos das pesquisas desenvolvidos no âmbito do Projeto "Urbanização, Condições de Vida e Mobilidade Espacial da População no contexto dos Biomas Nordestinos", financiado pelo Conselho Nacional de Desenvolvimento Científico \& Tecnológico (CNPQ) e conduzido pelo Professor Dr. Ricardo Ojima no Departamento de Demografia da Universidade Federal do Rio Grande do Norte.

Conforme indica o Dr. George Martine no Prefácio à obra, a migração rural-urbana no Brasil havia declinado drasticamente dos anos de 1970 para os anos 1980; nestes últimos anos declinam as taxas de fecundidade. À proporção que se aproxima o final do século, instala-se um ambiente de significativas alterações demográficas no qual o Nordeste passou a perder contingentes de população bem menores, a receber significativas migrações de retorno e, mais que isto, a acolher notável presença de imigrantes oriundos de outras áreas do Brasil. Este o panorama geral dentro do qual se movem os estudos apresentados a seguir.

No Capítulo 1, intitulado Migrações e Nordestinos pelo Brasil, Wilson Fusco e Ricardo Ojima pensam a história populacional do Nordeste do Brasil. Observam que na segunda metade do século 19, em 1872, a região continha $46 \%$ da população nacional recenseada, sendo a mais populosa do país. Atualmente a região contém cerca de $28 \%$ do total populacional do Brasil. A redução na participação, reconhece-se, decorreu das emigrações continuadas por mais de um século, não obstante o elevado crescimento natural da população regional nordestina. Este vasto movimento populacional emigratório é apresentado e discutido. Os nordestinos continuam a emigrar, contudo 
com muito menor intensidade. E, repita-se, há vigorosos movimentos de retorno, e fluxos de novos imigrantes, em direção à Região Nordeste.

No Capítulo 2, A Evolução das Migrações Interestaduais Cearenses 1960-2010, Silvana Queiroz e Rosana Baening expõem as principais tendências quanto ao volume e à direção dos fluxos de migrantes em resposta à dinâmica e às circunstâncias históricas e espaciais do desenvolvimento sócio econômico no Ceará, no Nordeste e no Brasil. O trabalho descreve e interpreta a movimentação populacional no Estado do Ceará desde a marcha para o Maranhão, nos anos de 1960, passando pela vaga no rumo da Região Sudeste nos anos de 1970 e o início e consolidação do descenso das perdas líquidas populacionais no Estado ao final do século 20; e as oscilações verificadas nestas perdas no começo do século atual.

O Capítulo 3 é dedicado ao tema da natureza seletiva das migrações: Migração $e$ Seletividade na Região Nordeste: um estudo a partir dos dados do censo demográfico de 2010. Ana Dantas e Flávio Freire analisam o efeito da migração sobre o diferencial de renda entre imigrantes e não imigrantes no Nordeste do Brasil, assim procedendo com o objetivo de verificar se os imigrantes na Região compõem ou não um grupo "positivamente selecionado". Os resultados apontam que estes imigrantes no Nordeste advêm em grande parte do Estado de São Paulo. Os autores concluem que os imigrantes seriam sim um grupo selecionado positivamente (melhor qualificação, melhores aptidões, mais espírito empreendedor, etc). Os resultados são também interpretados à luz da forte influência das redes de contatos e das migrações de retorno para o Nordeste.

Em “As Metrópoles Nordestinas no Processo Migratório Nacional”, o Capítulo 4, Cleber Oliveira, Wilson Fusco, Maria R. Lyra e J. M. Cunha abordam o ambiente no qual se desenvolve a dinâmica migratória nordestina, entendendo eles ser a Região Nordeste um locus privilegiado para os estudos migratórios. Entendem eles que não obstante o aumento na migração de retorno para a Região, assim como a redução dos fluxos Nordeste-Sudeste, a dinâmica das migrações regionais continuaria a ser impulsionada pelos mesmos elementos causais anteriores, como por exemplo a concentração da propriedade da terra, acreditam eles. A questão de "para onde", dentro do território regional do Nordeste, se dirigem os (i)migrantes de retorno - se para o município de origem do migrante, ou para município do interior ou para a Região Metropolitana - é detalhadamente examinada.

No Capítulo 5, “Análise das Migrações Intrarregionais no Semi Árido Setentrional”, Tiago Nascimento e Herick Oliveira observam que as migrações de longa distância oriundas da Zona das 
Caatingas em direção a outras macrorregiões do país estão diminuindo expressivamente. Estes migrantes estariam ultimamente se dirigindo cada vez mais para os centros urbanos - cidades médias polarizadoras - da própria área semiárida, enquanto os pequenos municípios exibem taxas de migração negativas. Nas últimas décadas, em comparação com as décadas de 1970 e 1980, verificou-se uma seletividade ligada à maior participação das mulheres no volume migratório produzido na zona semiárida, isto em decorrência das crescentes demandas exercidas pelas atividades do setor de serviços nos centros urbanos polarizadores da Região Nordeste para onde os migrantes se dirigem.

No Capítulo 6, Migração e Desigualdade de Renda na Região Nordeste, L. Lima e J. Neves retomam reflexões de Frederik Turner e M. Olson sobre estabilidade social e desigualdade econômica. A partir daí adotam a análise de regressão linear múltipla para avaliar a relação migração e desigualdade de renda no âmbito dos municípios do interior do Nordeste. Concluem eles que as maiores taxas de migração estão sim relacionadas a menores níveis de desigualdade de renda.

O Capítulo 7 - Urbanização, Dinâmica Migratória e Sustentabilidade no Semiárido Nordestino -, por R. Ojima, é dedicado à análise do processo de transição urbana nesta secção territorial do Nordeste. R. Ojima avalia as condições ambientais e de serviços urbanos dominantes e as suas associações com a dinâmica migratória especialmente dos fluxos rurais-urbanos na Região Nordeste.

No Capítulo 8 - Alterações Demográficas da População Local ao longo do Desenvolvimento da Região Turística: um estudo no Município de Tibau do Sul, RN -, N. Barros avalia as mudanças acontecidas nos padrões demográficos da população local residente na região da destinação turística denominada como Pipa (Município de Tibau do Sul), isto no período que se estende de 1991 a 2010. Estas mudanças foram interpretadas à luz do conhecido modelo ou teoria do ciclo dos resorts de R. Butler. N. Barros utiliza o método comparativo de contrastes entre duas áreas, examinando-lhes as mesmas variáveis. A unidade municipal que vai ser contrastada ou comparada com o Município de Tibau do Sul é o Município de Espírito Santo, situado no mesmo Estado e que não foi afetado por nenhuma dinâmica diferenciadora da estabilidade regional, ao contrário de Tibau, com a sua forte dinâmica turística.

O presente livro coletânea está disponível em Blucher Open Access (www.blucher.com.br; contato@blucher.com.br). 